\title{
A technique for intraoperative creation of patient-specific titanium mesh implants
}

\author{
Ian RP Sunderland MD FRCSC ${ }^{1}$, Glenn Edwards BES B Arch(Hons) MArch², \\ James Mainprize $\mathrm{PhD}^{2}$, Oleh Antonyshyn MD FRCSC ${ }^{2}$
}

\begin{abstract}
IRP Sunderland, G Edwards, J Mainprize, $O$ Antonyshyn. A technique for intraoperative creation of patient-specific titanium mesh implants. Plast Surg 2015;23(2):95-99.
\end{abstract}

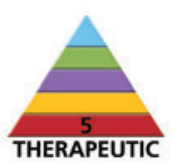

Prefabricated, patient-specific alloplastic implants for cranioplasty reduce surgical complexity, decrease operative times, minimize exposure and risk of contamination, and have resulted in improved aesthetic results. However, in creating a prefabricated custom implant using a patient's computed tomography data, a stable, unalterable defect must be clearly defined before surgery. In the event that an intraoperative modification of an exiting skull defect is required, or in cases of tumour resection in which the size of the skull defect is unknown preoperatively, these prefabricated implants cannot be used. The ideal method for alloplastic cranioplasty would enable cost-effective creation of a patient-specific implant with the capacity for intraoperative modification.

The present article describes a novel technique of cranioplasty that uses a patient's computed tomography data to create a custom forming tool (ie, mold), enabling intraoperative creation of a patient-specific titanium mesh implant. The utility of these implants in creating a custom reconstructive solution in cases in which the size of the skull defect is unknown preoperatively will be demonstrated using two case presentations.

Key Words: CAD/CAM; Cranioplasty; Calvarial reconstruction; Patientspecific implants; Titanium mesh

\section{Une technique de création intra-opératoire de résilles de titane adaptées aux patients}

En cranioplastie, les implants alloplastiques préfabriqués adaptés aux patients réduisent la complexité et la durée de l'opération, limitent l'exposition et le risque de contamination et donnent de meilleurs résultats esthétiques. Cependant, lors de la création d'un implant préfabriqué personnalisé au moyen de données tomodensitométriques sur le patient, il faut bien définir les anomalies non modifiables avant l'intervention. Lorsqu'il faut modifier une anomalie crânienne de sortie pendant l'opération ou qu'il faut réséquer une tumeur qui s'associe à une anomalie crânienne dont on ne connaît pas la dimension avant l'opération, ces implants préfabriqués ne sont d'aucune utilité. La cranioplastie alloplastique idéale consisterait à créer un implant adapté au patient susceptible d'être modifié pendant l'opération et dont le rapport coût-efficacité serait raisonnable.

Le présent article décrit une technique novatrice de cranioplastie qui fait appel aux données tomodensitométriques sur le patient pour créer un outil de formage personnalisé (un moule) à l'aide d'une résille de titane adaptée au patient pendant l'opération. Au moyen de deux présentations de cas, les auteurs démontrent l'utilité de ces implants pour créer une méthode de reconstruction adaptée lorsqu'on ne connaît pas la dimension de l'anomalie crânienne avant l'opération.
C alvarial reconstruction following trauma, tumour excision or craniotomy is a common procedure performed by craniofacial surgeons and neurosurgeons. Alloplastic cranioplasty using materials such as titanium mesh, polymethyl methacrylate (PMMA) and polyether ether ketone, offers many advantages over autologous cranioplasty including unlimited availability, elimination of donor site morbidity, permanent shape and volume retention, and relative ease of manipulation during surgery (1). In current practice, there are two primary methods of alloplastic cranioplasty: manual intraoperative contouring of the alloplastic cranioplasty material to fit the skull defect in situ; or use of prefabricated, patient-specific implants.

Simple skull defects are adequately reconstructed by manual intraoperative shaping of titanium mesh or molding of PMMA in situ. However, accurate restoration of normal skull shape by manual contouring is exceedingly difficult for large defects with complex surface geometry. Prefabricated patient-specific implants, designed using a patient's computed tomography $(\mathrm{CT})$ data to precisely restore the missing anatomy, are increasing in popularity as a surgical solution for these more complex cranial defects. These implants reduce surgical complexity, decrease operative times, minimize exposure and risk of contamination, and have resulted in improved cosmesis and patient satisfaction $(1,2)$.

The fabrication of custom implants normally relies on preoperative processing of the patient's CT data, the computer-assisted design of a virtual implant model and subsequent manufacture of the implant. The implant is prefabricated well in advance of surgery for a stable, unalterable skull defect that must be clearly defined before the planned operative procedure. Herein lies the major disadvantage of prefabricated, patient-specific cranioplasty implants. An unanticipated intraoperative finding requiring modification of the defect, renders the implant useless. More importantly, in all surgical procedures in which the size of the defect is not known before surgery, prefabricated implants cannot be used. Patient-specific implants are, therefore, not available to patients undergoing ablative tumour surgery, trauma surgery, or any cranial vault reconstructions potentially requiring intraoperative resection or modification.

The optimal method for alloplastic cranioplasty would enable costeffective creation of a patient-specific implant with the capacity for intraoperative modification. The present article describes a technique that uses a patient's CT scan data to create a custom forming tool (ie, mold) that enables intraoperative creation of a custom titanium mesh implant. These implants have the unique capacity for intraoperative modification in the event that the size of the defect is unknown preoperatively, or if alteration of an existing skull defect is required. Representative surgical cases will be presented, demonstrating the ability of this technique to achieve anatomical restoration of virtually any calvarial shape and contour.

\section{METHODS}

To date, eight patients have undergone patient-specific titanium mesh cranioplasty by the senior author (OA) at Sunnybrook Health Sciences Centre (Toronto, Ontario). Research ethics board approval was obtained to perform the present retrospective analysis. Information gathered from

\footnotetext{
${ }^{1}$ Division of Plastic and Reconstructive Surgery, University of Saskatchewan, Saskatoon, Saskatchewan; ${ }^{2}$ Division of Plastic and Reconstructive Surgery, University of Toronto, Toronto, Ontario

Correspondence: Dr Ian RP Sunderland, Medical Arts Building, 602-750 Spadina Crescent East, Saskatoon, Saskatchewan S7K 3 H3.

Telephone 306-653-7766, fax 306-653-7768, e-mail ian.r.sunderland@gmail.com
} 
TABLE 1

Patient information

\begin{tabular}{|c|c|c|c|c|}
\hline Case & $\begin{array}{c}\text { Age, } \\
\text { years/sex }\end{array}$ & Diagnosis & Skull defect location & $\begin{array}{l}\text { Skull defect } \\
\text { size, } \mathrm{cm}^{2}\end{array}$ \\
\hline 1 & $25 /$ male & $\begin{array}{l}\text { Frontal sinus } \\
\text { mucocele }\end{array}$ & $\begin{array}{l}\text { Right frontal bone, sinus, } \\
\text { anterior cranial vault }\end{array}$ & 30 \\
\hline 2 & 84/female & $\begin{array}{l}\text { BCC with } \\
\text { bony invasion }\end{array}$ & $\begin{array}{l}\text { Right fronto-temporo-parietal } \\
\text { region, anterior cranial } \\
\text { vault, lateral orbital wall }\end{array}$ & 80 \\
\hline 3 & $63 / \mathrm{male}$ & $\begin{array}{l}\text { Frontal sinus } \\
\text { mucocele }\end{array}$ & Frontal sinus & 43 \\
\hline 4 & 18/female & $\begin{array}{l}\text { Fibrous } \\
\text { dysplasia }\end{array}$ & $\begin{array}{l}\text { Right fronto-temporo-parietal } \\
\text { region }\end{array}$ & 39 \\
\hline 5 & 75/female & $\begin{array}{l}\text { BCC with } \\
\text { bony invasion }\end{array}$ & $\begin{array}{l}\text { Right frontal bone } \\
\text { including supraorbital } \\
\text { bar and orbital roof }\end{array}$ & 32 \\
\hline 6 & 20/male & Osteoma & $\begin{array}{l}\text { Right frontal bone, sinus, } \\
\text { anterior cranial vault }\end{array}$ & 33 \\
\hline 7 & $46 /$ male & Meningioma & $\begin{array}{l}\text { Right temporal bone and } \\
\text { anterior cranial vault, } \\
\text { lateral orbital wall }\end{array}$ & 50 \\
\hline 8 & $68 /$ male & $\begin{array}{l}\text { SCC with } \\
\text { bony invasion }\end{array}$ & Left frontal bone & 42 \\
\hline
\end{tabular}

BCC Basal cell carcinoma; SCC Squamous cell carcinoma

the charts included patient age, diagnosis, surgical site and defect size (Table 1). Cranioplasty was required for skull defects resulting from tumour extirpation in six patients and complicated frontal sinus mucoceles requiring craniectomy and calvarial reconstruction in two patients. In all cases, the ultimate size of the cranial defect was unknown preoperatively. Reconstruction was achieved using $0.6 \mathrm{~mm}$ titanium mesh (Stryker, USA), custom pressed intraoperatively using a patient-specific forming tool (Calavera Surgical Design, Canada), and secured to the calvarium using $1.7 \mathrm{~mm}$ titanium screws.

\section{TECHNIQUE OF CUSTOM CRANIOPLASTY}

High-resolution CT scans were obtained from all patients preoperatively. The skull CT data were converted into a three-dimensional (3D) surface representation using medical imaging processing software (Mimics-Materialise, Belgium) and prepared for the computer-aided design workflow. In all cases, the tumour or defect was unilateral, allowing for anatomical correction by mirroring the unaffected side, and the 3D surface data were then imported into haptics-based 3D modelling software (Freeform, Geomagic, USA) to further refine and complete the patient-specific designs. Next, molds were created using additive manufacturing software (Mimics-Materialise, Belgium) and a rapid prototype mold set made of composite plaster was fabricated using a 3D printer system (Zcorp, USA). The mold contours included patient-specific geometry that extended well beyond the margins of the expected defect to accommodate for the fact that the exact defect sizes were unknown preoperatively. The mold components were created for use in a custom pressing tool (Calavera Surgical Design, Canada). At the time of surgery, a mesh of appropriate size to cover the defect was selected, and the mold and press were used to create an implant that exactly restored normal skull contour (Figure 1). If needed, trimming of the mesh was performed before securing it into the defect. Because the design of the forming tools incorporated more of the calvarium than the expected defect, this could be performed while maintaining the perfect $3 \mathrm{D}$ geometry for the reconstruction.

\section{RESULTS}

The described technique of patient-specific titanium mesh cranioplasty was successfully applied in all eight patients. Excellent restoration of bony contour was achieved. With an average clinical follow-up of 12 months, there were no surgical infections, bleeding complications, cerebrospinal fluid leaks or reoperations for contour irregularities, hardware failures or other issues. Two case examples selected from Table 1 demonstrate the technique and its clinical application.

Case 2

An 84-year-old woman presented with a 28-year history of a basal cell carcinoma of the right frontotemporal region (Figure 2A). The lesion was massive ( $15 \mathrm{~cm}$ diameter), causing ptosis of the right brow and visual field obstruction. On examination the lesion was ulcerated and firmly adherent to the frontal bone. A CT scan demonstrated infiltration and destruction of the bone in the fronto-orbital region (Figures $2 \mathrm{~B}$ $2 \mathrm{C}$ and 2D). Metastatic workup was negative, and the patient was otherwise healthy and a good surgical candidate. Based on the infiltrative nature of the tumour, the exact size of the anticipated bony defect could not be accurately predicted preoperatively. The tumour was resected under frozen section control and a frontotemporal craniectomy of the underlying bone with an adequate margin was performed. A standard $0.6 \mathrm{~mm}$ sheet of titanium mesh was pressed into a patient-specific shape in the operating room, using a mold, a forming tool and a mechanical press (Figure 2E and 2F). The newly contoured implant was then fitted to remaining intact skeletal margins to completely reconstruct the missing anatomy (Figure $2 \mathrm{G}$ and $2 \mathrm{H}$ ). Soft tissue reconstruction was performed using an anterolateral thigh free flap, a temporalis muscle flap and numerous local flaps. Postoperative photos demonstrate the accuracy of anatomical restoration (Figure 2I and 2J).

\section{Case 3}

A 63-year-old healthy man presented with a one-year history of progressive swelling of the right forehead. The patient sustained a right fronto-orbital fracture at 16 years of age, necessitating a craniotomy and fracture reduction. He developed a fracture malunion featuring a depressed supraorbital rim and forehead which was treated in 1984 with obliteration of the frontal sinus, rib graft reconstruction of the supraorbital rim and acrylic frontal onlay cranioplasty. His subsequent course was uneventful until the past year, when he developed swelling in the area.

Preoperative CT scans revealed a mucocele in the residual frontal sinus, and fluid collection surrounding the overlying frontal acrylic implant. The underlying bone of the fronto-orbital area was resorbed and retruded, with multiple full-thickness defects (Figure 3A).

The surgical objective was to remove the acrylic implant, debride and excise infected bone, obliterate the frontal sinus and reconstruct the defect. The precise size and shape of the defect, however, could not be anticipated before surgery. Preoperative modelling of the optimal frontoorbital shape, based on the morphology of the contralateral intact skull, was performed, and a mold and forming tools were prepared.

Intraoperatively, the acrylic implant was removed (Figure 3B). A craniotomy and a radical frontal sinusectomy were performed (Figure 3C), and the frontal sinus was obliterated with cancellous iliac crest bone graft. The mold and forming tool were employed intraoperatively to press titanium mesh to a patient-specific shape (Figure 3D), which was then trimmed to fit the defect (Figure 3E). Accurate restoration of 3D cranial morphology was achieved (Figure 3F).

\section{DISCUSSION}

Calvarial defects in adults generally result from traumatic injuries, bone flap loss following craniotomy or tumour resection. Reconstruction is performed to protect the brain, re-establish normal skull contour and, in some cases, reverse the altered physiological state that may occur following craniotomy, the so-called 'syndrome of the trephined' (3-6).

Reconstruction with conventional bone grafting techniques, although ideal from the perspective of immunocompatibility, is both labour intensive and time consuming, and bone grafts in the skull have a propensity to undergo resorption even if rigid fixation is performed $(7,8)$. In addition, there are issues of limited supply, donor site morbidity and difficulties with precise contouring of the donor bone. To counteract these limitations and achieve permanent shape 


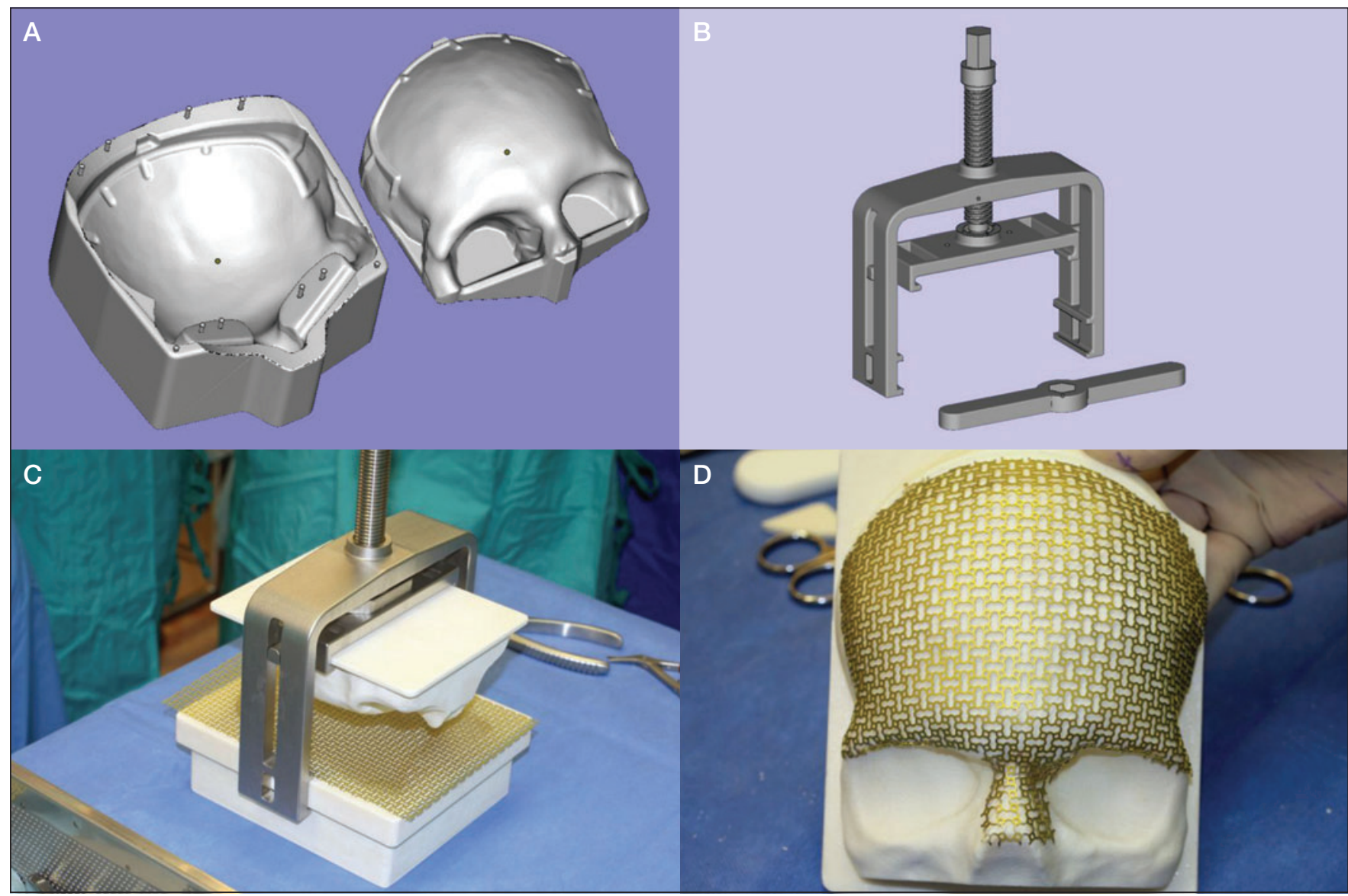

Figure 1) Technique for intraoperative creation of patient-specific titanium mesh implant. A Patient-specific mold of desired reconstruction and forming tool. B Mechanical press. C Intraoperatively, a sheet of titanium mesh is pressed. D Patient-specific implant with the desired geometry
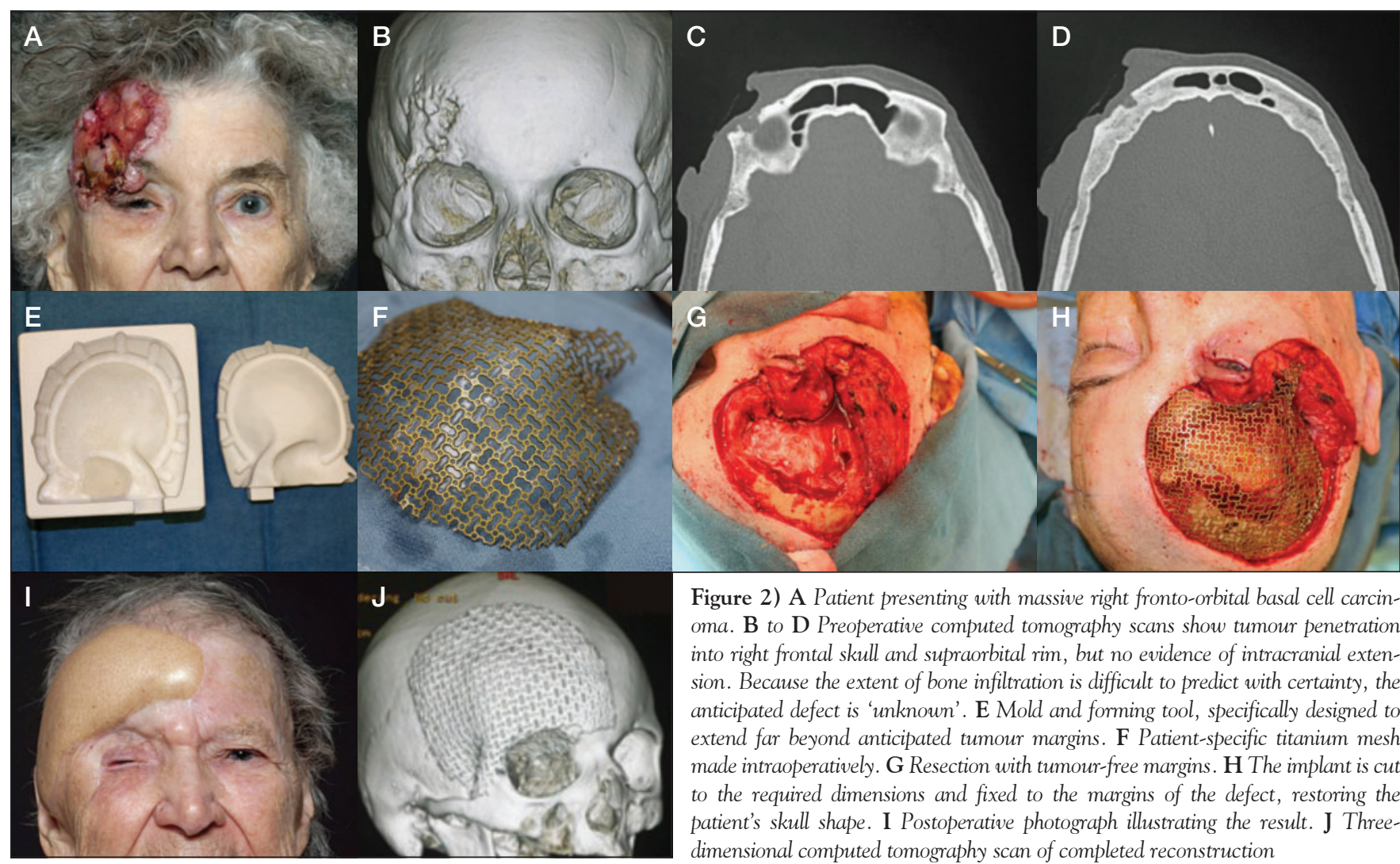

Figure 2) A Patient presenting with massive right fronto-orbital basal cell carcinoma. B to D Preoperative computed tomography scans show tumour penetration into right frontal skull and supraorbital rim, but no evidence of intracranial extension. Because the extent of bone infiltration is difficult to predict with certainty, the anticipated defect is 'unknown'. E Mold and forming tool, specifically designed to extend far beyond anticipated tumour margins. F Patient-specific titanium mesh made intraoperatively. G Resection with tumour-free margins. $\mathrm{H}$ The implant is cut to the required dimensions and fixed to the margins of the defect, restoring the patient's skull shape. I Postoperative photograph illustrating the result. J Threedimensional computed tomography scan of completed reconstruction 

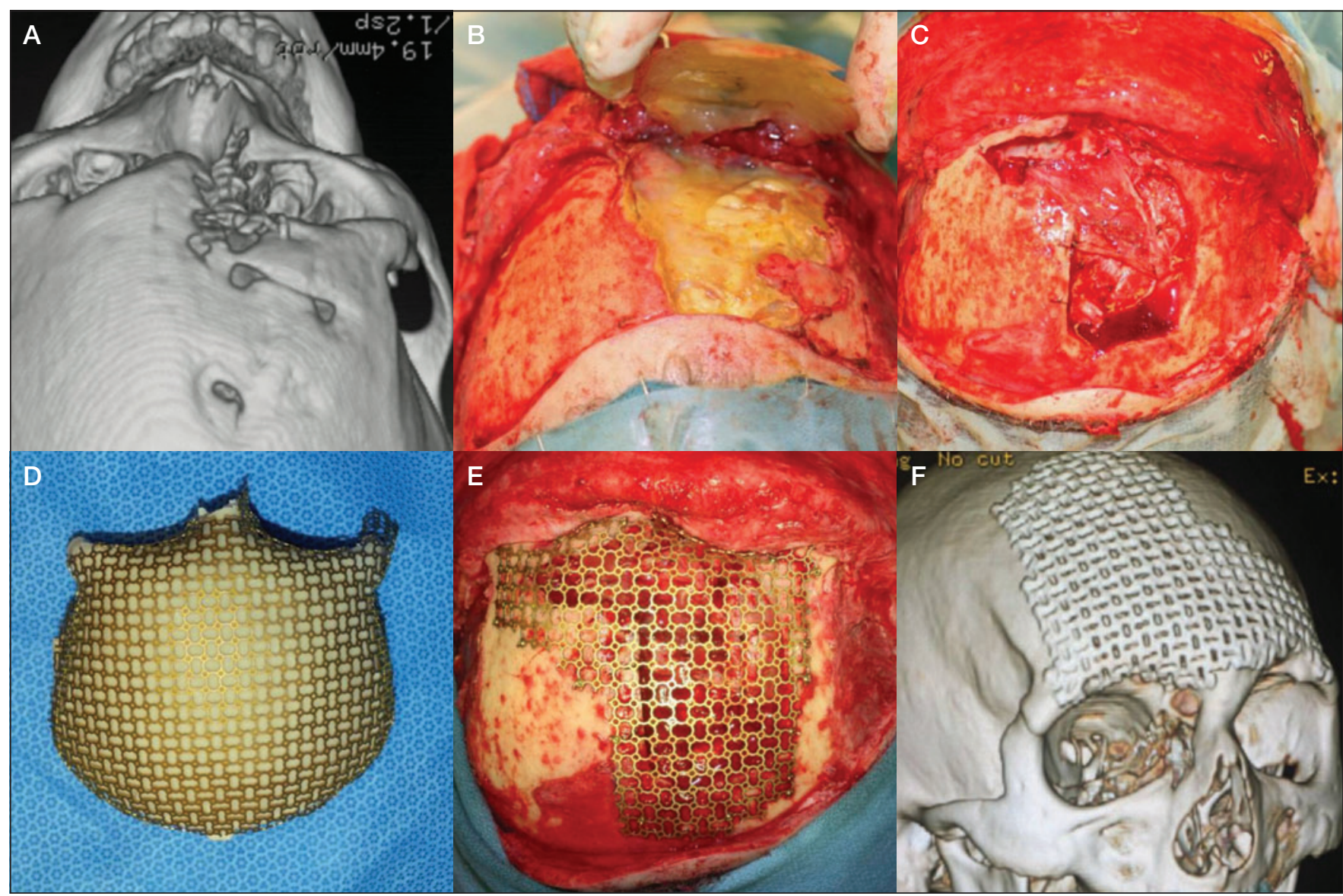

Figure 3) A Three-dimensional computed tomography scan demonstrating the underlying skeletal deformity resulting from fracture malunion, complicated by mucocele formation, infection and bone resorption. The margins of bone resection cannot be reliably predicted preoperatively. $\mathrm{B}$ Removal of the acrylic implant reveals underlying capsule and mucocele. C Intraoperatively, affected bone is resected, the frontal sinus is debrided and obliterated with cancellous bone graft. D The use of a patient-specific mold and forming tool facilitates intraoperative contouring of a titanium mesh. E Mesh trimmed and precisely fitted to restore normal contour. F Postoperative three-dimensional computed tomography scans demonstrate the final result

and volume retention in the reconstructed skull, many surgeons favor alloplastic cranioplasty with materials such as PMMA, hydroxyapatite, titanium mesh, polyether ether ketone and others.

Prefabricated, patient-specific alloplastic implants have proven exceedingly useful in the elective reconstruction of established, stable defects of the cranium. A number of computer-assisted design/computerassisted modelled techniques for custom implant creation have been described, predominantly using PMMA and titanium mesh (9-16). The techniques used vary from 'in house' solutions performed by the surgeons themselves to commercially available, industry manufactured implants. However, all prefabricated implants share a common goal: to precisely and permanently restore normal calvarial anatomy. Utilization of these techniques decreases surgical time, reduces time needed for postoperative recovery, lowers overall patient morbidity and optimizes aesthetic results (17).

Despite the many benefits of prefabricated, patient-specific implants, there are specific disadvantages that limit widespread application. First, the high costs associated with custom prefabricated implants generally restrict its application to only the most complex defects (18). Second, prefabricated implants are designed to fit a specific defect and are, therefore, limited to patients with fixed skull defects whose size and geometry are known preoperatively. Any intraoperative modification of the size, shape or bony margin of the defect renders the implant virtually useless. Clinically, this occurs under all circumstances in which a craniectomy is performed to remove bony tumours of the skull, osteoradionecrotic bone or osteomyelitic bone.
The technique described in the present article enables the surgeon to shape a custom, patient-specific titanium mesh implant intraoperatively for optimal anatomical restoration of an undefined, unknown defect. The drawbacks to manual contouring the alloplastic implant (increased operative time, increased risk of infection and poor aesthetic result) (2) are avoided, and the need for a two-stage surgery is obviated. The key to the success of this technique is the creation of a rapid prototyped mesh-forming tool manufactured to extend well beyond the margins of the expected defect. This accommodates for the fact that the exact defect sizes are unknown preoperatively. We prefer titanium mesh for the majority of our skull reconstructions due to its strength, malleability, ability for easy intraoperative modification, biocompatibility, low infection rate, and the fact that it can used for reconstructions adjacent to the paranasal sinuses $(1,17,19)$.

Puppa et al (20) described a case involving a patient with a large temporoparietal osteoma who underwent immediate cranioplasty with a prefabricated hydroxyapatite implant. However, the described technique was labour intensive, requiring a virtual craniotomy and neuronavigation. In addition, hydroxyapatite has been associated with a high rate of complications when used for reconstruction of full thickness calvarial defects (8).

To our knowledge, this is the first description of using patientspecific titanium mesh implants for skull defects whose exact size, shape, and location are unknown preoperatively. One drawback of this technique is the expertise required for design and manufacture of the rapid prototyped molds. However, the customs molds and press are commercially available and have a very short learning curve for the 
operative surgeon. Other potential drawbacks are the disadvantages of titanium mesh including cost, risk of exposure and potential scatter artifacts on CT imaging. However, the technique is versatile, decreases operative time, has a range of clinical applications, and leads to excellent clinical outcomes. The primary advantage over other custom implants is that this process specifically allows the surgeon to modify the patient-specific implant intraoperatively to accommodate virtually

\section{REFERENCES}

1. Spetzger U, Vougiokas V, Schipper J. Materials and techniques for osseus skull reconstruction. Minim Invasive Ther Allied Technol 2010;19:110-21.

2. Lee SC, Wu CT, Lee ST, Chen PJ. Cranioplasty using polymethyl methacrylate prostheses. J Clin Neurosci 2009;16:56-63.

3. Mokri B. Orthostatic headaches in the syndrome of the trephined: Resolution following cranioplasty. Headache 2010;50:1206-11.

4. Dujovny M, Agner C, Aviles A. Syndrome of the trephined: Theory and facts. Crit Rev Neurosurg 1999;9:271-8.

5. Agner C, Dujovny M, Gaviria M. Neurocognitive assessment before and after cranioplasty. Acta Neurochir 2002;144:1033-40.

6. Kuo JR, Wang CC, Chio CC, Cheng TJ. Neurological improvement after cranioplasty - analysis by transcranial Doppler ultrasonography. J Clin Neurosci 2004;11:486-89.

7. Grant GA, Jolley M, Ellenbogen RG, Roberts TS, Gruss JR, Loeser JD. Failure of autologous bone-assisted cranioplasty following decompressive craniectomy in children and adolescents. J Neurosurg Pediatrics 2004;100:163-8.

8. Moreira-Gonzalez A, Jackson IT, Miyawaki T, Barakat K, DiNick V. Clinical outcome in cranioplasty: Critical review in long-term follow-up. J Craniofac Surg 2003;14:144-53.

9. Cabraja M, Klein M, Lehmann TN. Long-term results following titanium cranioplasty of large skull defects. Neurosurg Focus 2009;26:E10.

10. Goh RCW, Chang CN, Lin CL, Lo LJ. Customised fabricated implants after previous failed cranioplasty. J Plast Reconstr Aesthet Surg 2010;63:1479-84.

11. Dean D, Min KJ, Bond A. Computer aided design of large-format prefabricated cranial plates. J Craniofac Surg 2003;14:819-32. any change in defect size or location, thereby making custom implants suitable for any patient.

DISCLOSURES: Oleh Antonyshyn, James Mainprize and Glenn Edwards are co-owners of Calavera Surgical Design, which manufactures the molds and presses used in this study.

12. Eufinger H, Wehmoller, Harders A, Heuser L. Prefabricated prostheses for the reconstruction of skull defects. Int J Oral Maxillofac Surg 1995;24:104-10.

13. Wulf J, Busch LC, Golz T, et al. CAD generated mold for preoperative implant fabrication in cranioplasty. Medicine meets virtual reality 13. Amsterdam: IOS Press, 2005:608-10.

14. Solaro P, Pierangeli, Pizzoni C, Boffi P, Scalese G. From computerized tomography data processing to rapid manufacturing of custom-made prostheses for cranioplasty. J Neurosurg Sci 2008;52:113-6.

15. Chiarini L, Figurelli S, Pollastri G, et al. Cranioplasty using acrylic material: A new technical procedure. J Craniomaxillofac Surg 2004;32:5-9.

16. Gerber N, Stieglitz L, Peterhans M, Nolte LP, Raabe A, Weber S. Using rapid prototyping molds to create patient specific polymethylmethacrylate implants in cranioplasty. Conf Proc IEEE Eng Med Biol Soc 2010:3357-60.

17. Tadros M, Constantino PD. Advances in cranioplasty: A simplified algorithm to guide cranial reconstruction of acquired defects. Facial Plast Surg 2008;24:135-45.

18. van Putten Jr, MC, Yamada S. Alloplastic cranial implants made from computed tomographic scan-generated casts. J Prosthet Dent 1992;68:103-8.

19. Ducic Y. Titanium mesh and hydroxyapatite cement cranioplasty: A report of 20 cases. J Oral Maxillofac Surg 2002;60:272-6.

20. Puppa AD, Mottaran, Scienza R. Image-guided cranial osteoma resection and bioceramic porous hydroxyapatite custom-made reconstruction in a one-step surgical procedure. Technical notes and illustrative case. Acta Neurochir 2010;152:155-9. 